University of Wollongong

Research Online

Faculty of Engineering and Information

Faculty of Engineering and Information

Sciences - Papers: Part A

Sciences

$1-1-2016$

\title{
The moderating impact of temporal separation on the association between intention and physical activity: a meta-analysis
}

\author{
Mairtin S. McDermott \\ University of Wollongong, mairtin@uow.edu.au \\ Rajeev Sharma \\ University of Wollongong, rajeev@uow.edu.au \\ Megan Andrews \\ University of Wollongong, mea816@uowmail.edu.au \\ Shahriar Akter \\ University of Wollongong, sakter@uow.edu.au \\ Donald Iverson \\ Advanced Manufacturing and Design Centre, iverson@uow.edu.au
}

See next page for additional authors

Follow this and additional works at: https://ro.uow.edu.au/eispapers

Part of the Engineering Commons, and the Science and Technology Studies Commons

\footnotetext{
Research Online is the open access institutional repository for the University of Wollongong. For further information
} contact the UOW Library: research-pubs@uow.edu.au 


\title{
The moderating impact of temporal separation on the association between intention and physical activity: a meta-analysis
}

\begin{abstract}
Previous meta-analyses have estimated that the intention-behaviour association in physical activity (PA) is large in magnitude. However, these prior meta-analyses have also revealed a large degree of heterogeneity, suggesting the presence of moderating variables. This study examines the impact of one such moderator, testing the hypothesis that the magnitude of the association between intention and behaviour decreases as the temporal separation between the two increases. A systematic literature search was used to identify published and unpublished studies that met the inclusion criteria. A randomeffects meta-regression was conducted to test the study hypothesis. A total of 78 journal articles and 11 unpublished dissertations were identified, yielding 109 effect sizes. The mean number of weeks between the measurement of intention and behaviour was $5.4(\mathrm{SD}=6.6$, range $=.43,26)$. The average correlation between intention and behaviour was $r=0.51$. In line with theoretical predictions, temporal separation was a significant moderator of the intention-behaviour correlation $(B=-.014, p<.001)$ and explained $24 \%$ of the between-study variance. This result remained unchanged when entered simultaneously with several control variables. The results of this analysis have important implications both for researchers and for intervention designers aiming to increase rates of PA.

\section{Disciplines}

Engineering | Science and Technology Studies

\section{Publication Details}

McDermott, M. S., Sharma, R., Andrews, M., Akter, S., Iverson, D., Caputi, P., Coltman, T. \& Safadi, M. (2016). The moderating impact of temporal separation on the association between intention and physical activity: a meta-analysis. Psychology, Health and Medicine, 21 (5), 625-631.
\end{abstract}

\section{Authors}

Mairtin S. McDermott, Rajeev Sharma, Megan Andrews, Shahriar Akter, Donald Iverson, Peter Caputi, Tim Coltman, and Murad Safadi 
4 Máirtín S McDermott ${ }^{\mathrm{a}}$, Rajeev Sharma ${ }^{\mathrm{a}}$, Megan Andrews ${ }^{\mathrm{b}}$, Shahriar Akter ${ }^{\mathrm{c}}$, Donald Iverson ${ }^{\mathrm{d}}$, 5 Peter Caputi ${ }^{\mathrm{b}}$, Tim Coltman ${ }^{\mathrm{c}} \&$ Murad Safadi ${ }^{\mathrm{a}}$.

6

7

${ }^{a}$ School of Computing and Information Technology, Faculty of Engineering and Information

Sciences, University of Wollongong, Northfields Avenue, New South Wales 2522, Australia.

${ }^{\mathrm{b}}$ School of Psychology, Faculty of Social Sciences, University of Wollongong, Northfields Avenue, New South Wales 2522, Australia.

${ }^{\mathrm{c}}$ School of Management, Operations and Marketing, Faculty of Business, University of Wollongong, Northfields Avenue, New South Wales 2522, Australia.

${ }^{\mathrm{d}}$ Faculty of Health, Arts and Design, Advanced Manufacturing and Design Centre, 453-477 Burwood Road, Hawthorn, Victoria 3122, Australia.

Corresponding author: Máirtín McDermott (mairtin@uow.edu.au)

\section{Word count: 1581}




\section{Abstract}

Previous meta-analyses have estimated that the intention-behaviour association in physical activity is large in magnitude. However, these prior meta-analyses have also revealed a large degree of heterogeneity, suggesting the presence of moderating variables. The present study examines the impact of one such moderator, testing the hypothesis that the magnitude of the association between intention and behaviour decreases as the temporal separation between the two increases. A systematic literature search was used to identify published and unpublished studies that met the inclusion criteria. A random-effects meta-regression was conducted to test the study hypothesis. A total of 78 journal articles and 11 unpublished dissertations were identified, yielding 109 effect sizes. The mean number of weeks between the measurement of intention and behaviour was $5.4(\mathrm{SD}=6.6$, range $=0.43,26)$. The average correlation between intention and behaviour was $r=0.51$. In line with theoretical predictions, temporal separation was a significant moderator of the intention-behaviour correlation $(B=-0.014, p<0.001)$ and explained $24 \%$ of the between-study variance. This result remained unchanged when entered simultaneously with several control variables. The results of this analysis have important implications both for researchers and for intervention designers aiming to increase rates of physical activity.

Keywords: Intention; behaviour; physical activity; temporal separation; meta-analysis. 


\section{Introduction}

Increasing the intention to act is an important aim of many behaviour change interventions, such as those aiming to increase levels of physical activity (PA). This is due to intention being viewed as the variable most proximal to behaviour by several commonly used models. Previous metaanalyses have estimated the intention-behaviour (I-B) association to be between $r=0.45$ and 0.51 (Hagger, Chatzisarantis, \& Biddle, 2002; McEachan, Conner, Taylor, \& Lawton, 2011). However, those meta-analyses have also revealed a large degree of heterogeneity, suggesting that the I-B association needs to be examined for the presence of moderating variables.

The period of temporal separation between the measurement of intention, typically assessed using mixed measures of participants' self-ratings of intention, expectation and desire (Armitage \& Conner, 2001), and the measurement of behaviour, also typically assessed using self-reports (McEachan et al., 2011), has been argued to be an important moderator of the I-B relationship in PA (Downs \& Hausenblas, 2005; McEachan et al., 2011). Increasing periods of temporal separation are considered likely to attenuate the strength of the I-B association as with longer time periods an individual will have more opportunities to be exposed to new experiences and information that might lead to a change in intention (Ajzen \& Madden, 1986). This may be a particularly critical issue for PA, as the health benefits of exercise accrue only after individuals have engaged in that behaviour regularly over a sustained period of time.

\section{Prior research and its limitations}

Two previous meta-analyses have examined the moderating effect of temporal separation on the I-B association in PA (Downs \& Hausenblas, 2005; McEachan et al., 2011). Although these studies produced findings that were largely consistent with theoretical predictions, both are 
limited from both a methodological and practical standpoint. From a methodological perspective, the studies have two key limitations. First, neither study employed control variables while analysing the effect of temporal separation. Second, both studies employed sub-group analysis ( $\leq$ one week, one week to one month, one month to one year and $\leq 5$ weeks, $>5$ weeks, respectively) to investigate differences in the magnitude of I-B associations across potentially arbitrary, researcher-defined categories of temporal separation. This latter point is also limiting from a practical standpoint, as it prevents these studies from providing a reliable estimate of the magnitude of the moderating effect, i.e. an estimate of the rate at which the predictive validity of intention falls over time.

The current meta-analysis, therefore, aims to build on prior research by addressing the above limitations. Specifically, by employing random effects meta-regression to test the impact of temporal separation defined as a continuous variable, whilst controlling for the effects of variables found previously to moderate the I-B association in PA: participants' age, publication type and the methods used to measure behaviour (Downs \& Hausenblas, 2005; Hagger et al., 2002; McEachan et al., 2011). 


\section{Methods}

\section{Selection criteria and study identification}

The Preferred Reporting Items for Systematic Reviews and Meta-Analyses (PRISMA (Moher, Liberati, Tetzlaff, \& Altman, 2009) guidelines were followed throughout the design and conduct of this systematic review. We included studies published in English where: the target population was adults aged 18-65, without any current or former medical conditions; the target behaviour was operationalised as physical activity or exercise; and where reported outcomes included bivariate correlations between intention and PA measured at a subsequent time point. Studies in which participants received an intervention were excluded. We searched PsycINFO, MEDLINE, Web of Science, CINAHL, and ProQuest Dissertations and Theses. We also scanned the reference lists of previous meta-analyses incorporating data on the I-B relationship in PA. All titles and abstracts from the formal electronic searches were pre-screened by one review author (MSMcD) for possible inclusion. Those selected were then subject to full-text assessment by the same author, with the accuracy of inclusions checked by a second (MA).

\section{Data extraction}

We extracted correlation data, sample size and the period of temporal separation between intention and behaviour (in weeks). In line with previous reviews (Downs \& Hausenblas, 2005; Hagger et al., 2002) we coded the age of participants as either $18-25$ or $26-65$ and publication type as either a journal article or dissertation. To control for risk of bias in included studies, we coded each correlation for the method used to measure behaviour. Following Sharma, Yetton \& Crawford (2009), a four-point ordinal scale ordered as: archival (1); behaviourally continuous (2); behaviourally anchored (3); or perceptually anchored (4) was employed. 
106 Calculation of the pooled mean effect size $(r)$ was conducted using inverse-variance weighted 107 random effects meta-analysis (Borenstein, Hedges, Higgins, \& Rothstein, 2009). We also 108 estimated the heterogeneity across studies, using both the $Q$ and $I^{2}$ statistics (Higgins, Thompson, 109 Deeks, \& Altman, 2003). To test for the moderating impact of temporal separation, we employed 110 the protocol for random effects meta-regression recommended by Borenstein et al. (2009). 111 Visual inspection of scatterplots and examination of Cook's distance (Field, 2005) for each 112 included effect size were used to identify outliers. Based on this analysis, one study was 113 excluded. The remaining effect sizes had a maximum temporal separation of 26 weeks. All 114 analyses were performed using Comprehensive Meta-Analysis (CMA) Version 3.0 (Borenstein, 115 Hedges, Higgins, \& Rothstein, 2014). 


\section{Results}

The electronic search strategy retrieved 8517 unique records. A further 49 were identified through screening the reference lists of related meta-analyses. In total, 77 journal articles and 11 dissertations met the inclusion criteria. Details of the screening process can be seen in Figure 1.

\section{FIGURE 1 NEAR HERE}

Data from seven studies were reported in more than one article. Relevant information was extracted from either as appropriate. Three articles reported data from two studies. Eighty-four studies were therefore included yielding 109 effect sizes between PA intention and behaviour with a total $n=31,870$. A list of articles included in the meta-analysis is available in Supplementary File 1. An overview of study characteristics is presented in Table 1. The randomeffects meta-analysis showed that the average correlation between intention and behaviour was $r$ $=0.51\left(95 \%\right.$ CI: 0.48, 0.54). Examination of the $Q$-statistic $(Q=1473.69, p<0.001)$ and $I^{2}$ $(92.67 \%)$ indicated significant heterogeneity, supporting the use of meta-regression to explore moderators such as temporal separation.

\section{TABLE 1 NEAR HERE}

The results of the meta-regression show that temporal separation in weeks was a significant moderator of the I-B correlation $(B=-0.014, p<0.001)$ explaining $24 \%$ of the between-study variance in the I-B relationship. A breakdown of average correlations for each period of temporal separation can be seen in Supplementary File 2. This result remained unchanged when temporal 
140 separation was entered simultaneously with control variables $(B=-0.013$ [95\% CI: -0.020 , $141-0.007] p<0.001$ ) (see Table 2). Together, these variables accounted for $36 \%$ of the between142 study variance in the I-B association.

143

144

TABLE 2 NEAR HERE

145 


\section{Discussion}

147 Identifying the precise nature of the relationship between behaviour and cognitive antecedents such as intention is of clear importance to those aiming to develop effective interventions for increasing rates of physical activity. The results of the current meta-analysis represent the most robust evidence to date in support of one of the key assumptions of the I-B relationship, specifically that the correlation between intention and behaviour decreases as the period of temporal separation between intention and behaviour increases. To our knowledge, the current meta-analysis is also the first to provide an estimate of the magnitude of the moderating effect of temporal separation.

This study has some strengths and limitations. A comprehensive search strategy was employed to identify both published and unpublished studies that met the inclusion criteria. In addition, temporal separation was operationalized as a continuous variable, allowing for a more reliable determination of its moderating impact compared with those studies employing potentially arbitrary categories of time intervals. Finally, a robust examination of the impact of temporal separation was conducted whilst controlling for methodological, participant and studylevel control variables.

Against this, it is worth noting that despite controlling for key covariates, and the inclusion of a sample of studies that were largely homogenous in terms of participants and definitions of intention and behaviour, reported heterogeneity remained high $(Q=897.42, p<$ $0.001, I^{2}=88.63 \%$ ) suggesting the presence of other moderators not accounted for in this analysis. Furthermore, the included studies restrict our ability to track how the I-B association develops beyond six months. We identified only one effect size where the period of temporal separation exceeded this time point, and this was excluded from the main analysis after being 
identified as an outlier. Based on the current analysis, however, which found that the I-B correlation decreased on average by 0.013 each week over the 26 weeks from the intercept (i.e. 0 weeks) of $r=0.459$ (see Table 2), it seems unlikely that intention would continue to predict behaviour to a meaningful degree beyond this point. This is important since it takes time for the health benefits of physical activity to accrue. Each of these limitations represents a matter for further empirical research.

In conclusion, the findings of this meta-analysis suggest that although the overall I-B association in PA is moderate, it is significantly moderated by temporal separation to the extent that predicted levels of the association are negligible at six months. Further research is required to determine the persistence of the association beyond this time point. Although the current analysis controlled for different potential sources of bias, reported heterogeneity remained high which indicates the presence of moderators not controlled for here. Meta-analyses, incorporating a broader range of moderators may be required to gain a more complete understanding of the progression of the I-B relationship in PA over time. The implications of this meta-analysis are threefold: (a) to maximize predictive capacity of the I-B relationship, researchers should focus on predicting PA behaviour in the short term; (b) it might be prudent for those planning interventions to incorporate multiple 'top ups' of intervention elements targeting intentions over time. This latter point is further supported by findings that a similar pattern appears to emerge in experimental studies (Webb \& Sheeran, 2006), and (c) given the extent to which the magnitude of the I-B association decreases over time, the utility of intention as a predictor of meaningful levels of PA appears questionable. 


\section{References}

Ajzen, I., \& Madden, T. J. (1986). Prediction of Goal-Directed Behavior - Attitudes, Intentions, and Perceived Behavioral-Control. Journal of Experimental Social Psychology, 22(5), 453-474.

Armitage, C. J., \& Conner, M. (2001). Efficacy of the theory of planned behaviour: A metaanalytic review. British Journal of Social Psychology, 40, 471-499.

Borenstein, M., Hedges, L., Higgins, J., \& Rothstein, H. (2014). Comprehensive Meta-Analysis. Version 3. Englewood, NJ: Biostat.

Borenstein, M., Hedges, L. V., Higgins, J. P. T., \& Rothstein, H. R. (2009). Introduction to metaanalysis. Chichester: John Wiley \& Sons.

Downs, S. D., \& Hausenblas, H. A. (2005). The theories of reasoned action and planned behaviour applied to exercise: A meta-analytic update. Journal of Physical Activity and Health, 2, 76-97.

Field, A. (2005). Discovering statistics using SPSS (Second Edition). London: Sage Publications.

Hagger, M. S., Chatzisarantis, N. L. D., \& Biddle, S. J. H. (2002). A meta-analytic review of the theories of reasoned action and planned behavior in physical activity: Predictive validity 
and the contribution of additional variables. Journal of Sport \& Exercise Psychology, 24(1), 3-32.

215

Higgins, J. P., Thompson, S. G., Deeks, J. J., \& Altman, D. G. (2003). Measuring inconsistency in meta-analyses. $B M J, 327(7414), 557-560$.

Webb, T. L., \& Sheeran, P. (2006). Does changing behavioral intentions engender behavior change? A meta-analysis of the experimental evidence. Psychological Bulletin, 132(2), 249-268.

230 
Figure 1: PRISMA flow chart

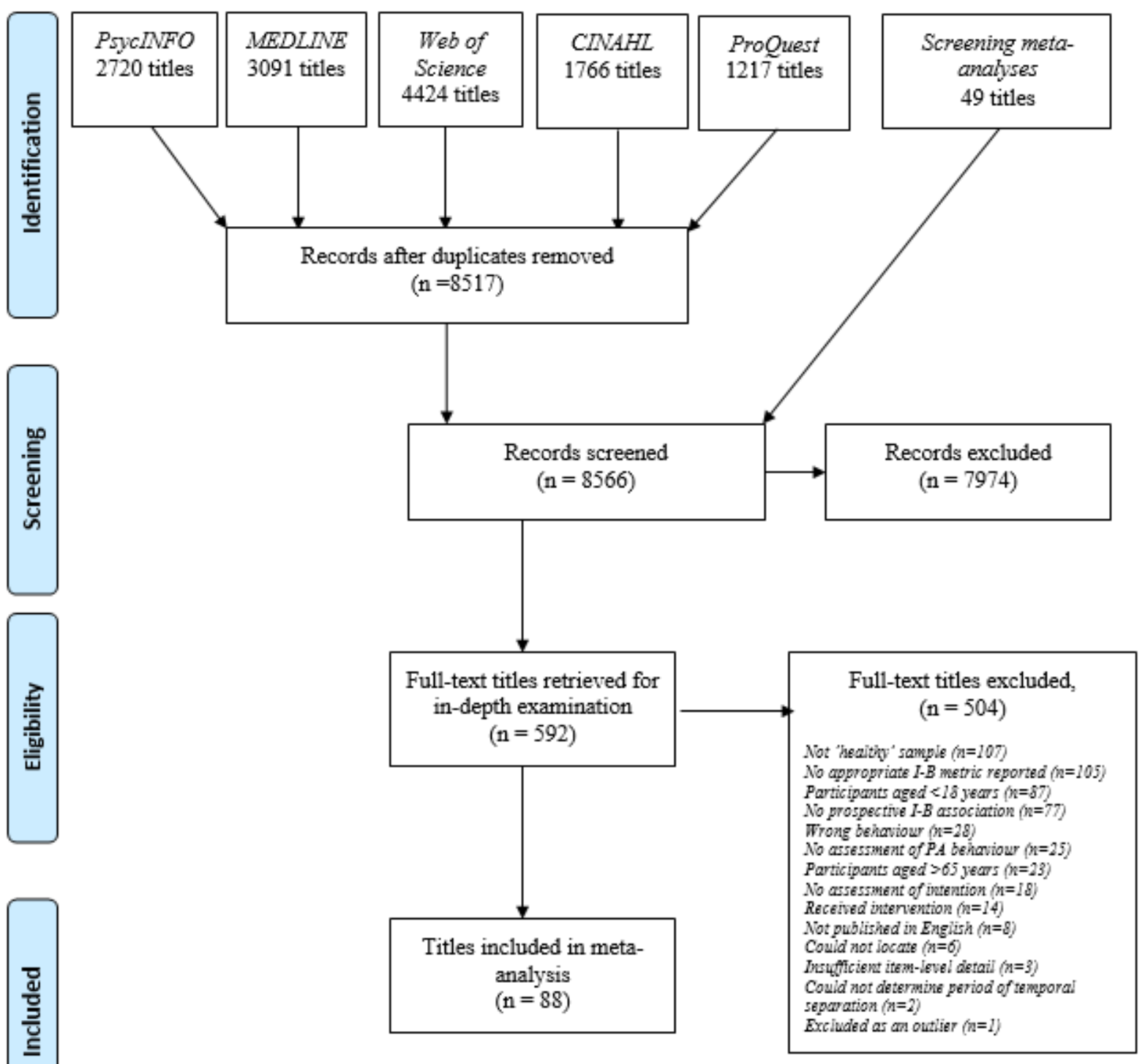


Table 1: Characteristics of included studies $(n=84)$

\section{Participants \% (n)}

University Students

$67.9(57)$

Company employees

$11.9(10)$

Recruited from the community

$7.1(6)$

Other

$7.1(6)$

Random sampling

$5.6(5)$

Theoretical Framework

Theory of Planned Behaviour

$77.4(65)$

Multiple theories

$14.3(12)$

Health Action Process Approach

$4.8(4)$

Other theories

$3.6(3)$

Temporal Separation (Mean (SD), Range)

$5.4(6.6), 0.43-26$

Sample size (Mean (SD), Range)

$292.4(271.7), 22-1582$

Table 2: Meta-regression of the impact of temporal separation on the I-B association in PA

with covariates.

\begin{tabular}{|lcccccc|}
\hline \multicolumn{1}{|c}{ Variable } & Coefficient & $\begin{array}{c}\text { Standard } \\
\text { error }\end{array}$ & Z-value & p-Value & \multicolumn{2}{c|}{$\begin{array}{c}\text { 95\% } \\
\text { confidence } \\
\text { interval }\end{array}$} \\
\hline $\begin{array}{l}\text { Temporal separation } \\
\text { (weeks) }\end{array}$ & -0.013 & 0.003 & -3.93 & 0.0001 & -0.020 & -0.007 \\
Behaviour Method Type & 0.125 & 0.034 & 3.68 & 0.0002 & 0.059 & 0.192 \\
Publication type & -0.070 & 0.060 & -1.18 & 0.2393 & -0.187 & 0.047 \\
Participant age & -0.003 & 0.002 & -1.14 & 0.2534 & -0.007 & 0.002 \\
Intercept & 0.459 & 0.120 & 3.83 & 0.0001 & 0.224 & 0.694 \\
\hline
\end{tabular}

Notes: Temporal separation was entered in weeks. Behaviour method type was coded as: system captured (1), behaviourally continuous (2), behaviourally anchored (3) or perceptually anchored (4). Multiple codings within measures were possible due to variation in method type across items. Publication type was coded either as a peer reviewed journal article (1) or unpublished dissertation (2). Participant age was coded as 18-25 (1) or 26-65 (2). 